\title{
Behaviour of fibre-reinforced cementitious composite containing high- volume fly ash at elevated temperatures
}

\author{
KIM HUNG MO*D, ZHI PIN LOH, CHEE GHUAN TAN, U JOHNSON ALENGARAM and \\ SOON POH YAP
}

Department of Civil Engineering, Faculty of Engineering, University of Malaya, 50603 Kuala Lumpur, Malaysia e-mail: khmo@um.edu.my; khmo890815@gmail.com

MS received 28 September 2017; revised 7 May 2018; accepted 10 May 2018; published online 18 September 2018

\begin{abstract}
This research describes the properties of acrylic fibre-reinforced cementitious composite containing high-volume fly ash. In this investigation, the fly ash content (30\% and 60\%) and the acrylic fibre dosage (0\%, $1 \%$ and $2 \%$ ) were varied. Increased content of fly ash in the composite was found to be able to partially compensate the reduction in workability caused by the inclusion of fibres. On the other hand, although the use of fibres had minimal influence on the compressive strength, the fibres could significantly enhance the flexural strength of the composite, particularly in the composite containing higher fly ash content. At elevated temperatures, it was found that the inclusion of acrylic fibres was beneficial in the composite with higher fly ash content, as demonstrated by the increased strength retention and reduced spalling damage at elevated temperature.
\end{abstract}

Keywords. Fibre-reinforced composite; high-volume fly ash; acrylic fibre; elevated temperature.

\section{Introduction}

The low tensile strength in cement-based materials is commonly associated with the brittle behaviour and cracking vulnerability. Cracking in cement-based materials such as concrete not only affects the durability and service life of structures, but also the safety of structures constructed using the material could also be compromised. The need to compensate for the low tensile strength of cementbased materials has since encouraged the incorporation of fibre reinforcement. However, in order to significantly improve the tensile strength, high volume of fibres (about $1-3 \%$ ) is usually required. This in turn creates workability issue of the resulting composite as high volume of fibres can cause fibre-balling problems. Hence, high amounts of cement as well as fly ash are required to form the binder to ensure that all of the fibres could be mixed homogenously. In particular, the use of fly ash has an important role in controlling the amount of cement used as well as enhancing the workability of the composite. The combination of these materials, namely the binder, fine aggregate, fibre and water, forms a composite generally known as fibre-reinforced cementitious composite (FRCC).

*For correspondence
Research in the past revealed that synthetic fibres such as polyvinyl alcohol (PVA) contributed towards enhancement of the mechanical performance and ductility of FRCC [1]. In fact, a number of recent works focused on utilization of non-conventional fibres for FRCC such as jute fibre [2], bagasse fibre [3] and wood fibre [4]. Despite this, limited investigations were carried out with respect to the behaviour of FRCC when exposed to elevated temperature. The understanding of the performance at high temperature is critical for structures particularly in the event of fire, as well as the use in applications such as liner in clinker storage silos, concrete chimney, containment vessels of power plant and more [5]. High temperature poses risk to cement-based materials as the material could degrade and lose strength, resulting in loss of loadbearing ability as well as causing sudden, explosive failures in structures. It is known that the explosive spalling in concrete exposed to high temperatures depends on various factors such as moisture content, type of concrete, type of aggregate used and rate of heating. By preventing explosive spalling, the concrete could still retain certain portion of compressive strength, though there will be significant losses at higher temperature, primarily due to the decomposition of calcium silicate hydrate. There are numerous investigations that demonstrated beneficial effects towards fire resistance through the inclusion of fibres in cement-based materials. For instance, the addition of polypropylene (PP) fibres was found to reduce the 
risk of spalling in concrete, which was attributed to the melting of fibres, which increased permeability and reduced built-up pressure within the concrete [6]. Steel fibre, on the other hand, was more beneficial in reducing spalling in high-performance concrete, which was more susceptible towards such risk at elevated temperature compared with ordinary concrete [7]. Besides this, utilization of supplementary cementitious materials (SCM) such as fly ash and blast furnace slag to partially replace cement was found to be useful in reducing the strength deterioration of cement-based materials that were exposed to high temperatures [8, 9]. For instance, it was revealed that in concrete containing fly ash, the compressive strength could be increased at elevated temperature of $400{ }^{\circ} \mathrm{C}$ whereas lower compressive strength loss or better strength retention was also found upon exposure to elevated temperature of $800{ }^{\circ} \mathrm{C}$, as reported by Rashad [10] and Seleem et al [11], respectively. At these elevated temperatures, as there was no explosive spalling damage, the concrete could exhibit residual strength and the improvement in the concrete containing fly ash was attributed to the possible formation of tobermorite and new mineral compounds at the temperatures of 400 and $800{ }^{\circ} \mathrm{C}$, respectively.

Limited studies, however, were conducted with respect to the combined use of fibres and SCM. A few studies indicated that there is positive interaction between fibres and SCM in concrete, whereby the presence of SCM can enhance the effectiveness of fibres. Kayali [12] suggested that the use of fly ash can enhance the fibre-matrix bond due to the pozzolanic reaction, which produced denser interfacial transition zone. Alhozaimy et al [13] also reported more effective use of PP fibres in the presence of pozzolans. Although a few studies were carried out in the past on the combined effects of SCM and low-volume polymeric fibres related to the resistance of cement-based materials towards elevated temperatures, these literatures were confined to different types of cement-based materials such as reactive powder concrete [14], ordinary concrete [15] and lightweight concrete [16] .

Since there is limited information with regard to the fire resistance of cementitious composite containing SCM and polymer fibres, it is imperative to assess the combined effects of these materials on the resistance of the composite towards high-temperature exposure. Hence, the main objective of this research is to investigate the effects of high-volume fly ash and polymeric-type acrylic fibres on the resistance of FRCC at elevated temperature. Specifically, the fly ash will be used as $30 \%$ and $60 \%$ of the total binder content, while the acrylic fibres dosages are $1 \%$ and $2 \%$ and the resulting composite will be subjected to elevated temperatures of 400 and $800{ }^{\circ} \mathrm{C}$. The study is essential as in-depth knowledge of the performance of FRCC at elevated temperature is necessary for the development and future application of the composite in structural application.

\section{Experimental programme}

\subsection{Materials}

The binder used in this investigation consists of type I ordinary Portland cement and low calcium fly ash. River sand passing through sieve size of $1.18 \mathrm{~mm}$ was used as fine aggregate in this study. The specific gravity and water absorption of the river sand were determined to be 2.62 and $0.3 \%$, respectively. Laboratory tap water was used as mixing water in the investigation. Additionally, a polycarboxylate-ether-based superplasticizer (SP) with commercial name of Sika Viscocrete-2055 was used as the water reducer and to facilitate workability of FRCC. A polymeric-type monofilament acrylic fibre was added to produce the FRCC. The acrylic fibre had a length of $12 \mathrm{~mm}$ with diameter of $9 \mu \mathrm{m}$. The appearance of the monofilament acrylic fibre under scanning electron microscopy (SEM) is shown in figure 1.

\subsection{Mix proportion}

A total of six mixes were prepared for this investigation as listed in table 1 . The variables include the fly ash/total binder content, namely $30 \%$ and $60 \%$, as well as the dosage of fibres incorporated, which was $0 \%, 1.0 \%$ and $2.0 \%$.

\subsection{Mixing procedure}

Initially, the powder materials, namely cement and fly ash as well as the fine aggregate, were dry mixed in a mortar mixer for $1 \mathrm{~min}$. This was followed by the addition of water

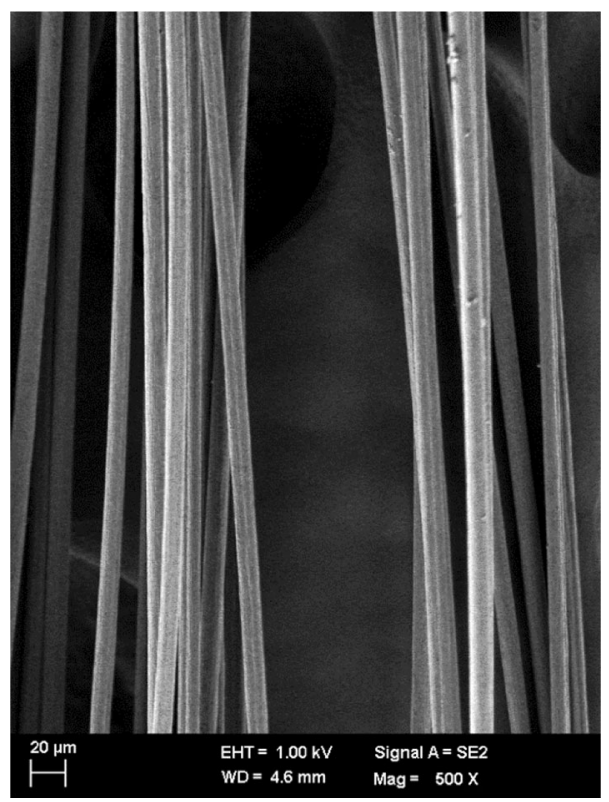

Figure 1. SEM picture of monofilament acrylic fibre. 
Table 1. Mix proportions of FRCC.

\begin{tabular}{lcccccr}
\hline & \multicolumn{6}{c}{ Content $\left(\mathrm{kg} / \mathrm{m}^{3}\right)$} \\
\cline { 2 - 7 } Mix & Cement & Fly ash & Sand & Water & SP & Fibre \\
\hline C0 & 840 & 360 & 453 & 396 & 2.4 & 0 \\
C1 & 840 & 360 & 427 & 396 & 2.4 & 12 \\
C2 & 840 & 360 & 401 & 396 & 2.4 & 24 \\
F0 & 480 & 720 & 375 & 396 & 2.4 & 0 \\
F1 & 480 & 720 & 349 & 396 & 2.4 & 12 \\
F2 & 480 & 720 & 323 & 396 & 2.4 & 24 \\
\hline
\end{tabular}

and SP with further mixing for 2 min. Lastly, the fibres were added and mixed until a homogenous mixture was attained with no balling of fibres. Upon completion of mixing, the fresh FRCC was subjected to flow table test to determine the workability and then compacted in steel moulds. The specimens were de-moulded after 1 day and water-cured until the age of testing.

\subsection{Test method}

The workability of the FRCC was determined based on the flow table test as stipulated in ASTM C1437-07. The mould was fully filled with tamped fresh FRCC in layers and the flow table supporting the mould was jolted 25 times in $15 \mathrm{~s}$. Upon removal of the mould, the diameter of the fresh FRCC spread out was determined as the flow diameter.

The compressive strength test was carried out on cube specimens measuring $50 \times 50 \times 50 \mathrm{~mm}^{3}$ at 7 and 28 days, respectively. The test was done in accordance with BS EN 12390-3: 2009 with a loading rate of $1.5 \mathrm{kN} / \mathrm{s}$. Flexural strength test was carried out on prismatic specimens with nominal dimensions of $40 \times 40 \times 160 \mathrm{~mm}^{3}$ based on ASTM C348-02 at the age of 28 days. Three-point loading was adopted in testing the prismatic specimens for flexural strength.

For the determination of the residual strength of the FRCC upon exposure to elevated temperature, the $50 \times 50 \times 50 \mathrm{~mm}^{3}$ cube specimens were placed inside a muffle furnace at temperatures of 400 and $800{ }^{\circ} \mathrm{C}$ for $1 \mathrm{~h}$, and then allowed to cool internally for a further hour before the furnace was opened. The residual strength of the FRCC was determined by subjecting the cube specimens to compressive strength test in accordance to BS EN 12390-3: 2009 with a loading rate of $1.5 \mathrm{kN} / \mathrm{s}$ when the specimens were cooled sufficiently to be handled.

\section{Results and discussion}

\subsection{Workability}

It was observed that for the fresh mixes without fibres, namely $\mathrm{C} 0$ and $\mathrm{F} 0$, the flow spread was at the maximum diameter of the flow table plate, which was $250 \mathrm{~mm}$. This showed that the mixes had high workability and neither bleeding nor segregation was observed. However, upon inclusion of $1.0 \%$ acrylic fibres, mixes $\mathrm{C} 1$ and $\mathrm{F} 1$ exhibited reduced flow diameter, which was determined to be 182 and $185 \mathrm{~mm}$, respectively, which was about $27 \%$ less than the control mixes. Further increase in the dosage of fibres to $2.0 \%$ resulted in decreased flow diameter of 117 and $126 \mathrm{~mm}$, respectively, for the mixes $\mathrm{C} 2$ and $\mathrm{F} 2$. The reduction in flow diameter of cement mortar due to inclusion of acrylic fibres was also previously reported [17, 18]. The apparent trend of flow reduction due to the use of fibres was likely due to the increase demand for binder to coat the fibres. Moreover, it was observed that the fibres could form a network structure [19], which restrained the flow and increased the stiffness of the resulting composite, possibly decreasing the workability of the fresh FRCC. Flores Medina et al [20] also suggested lack of fibre flexibility as one of the reasons for causing fibre balling effect, which reduced workability of concrete. On the other hand, based on the comparison of flow diameter between mixes $\mathrm{C} 2$ and F2, it could be observed that the higher amount of fly ash contributed towards increased flow diameter of the FRCC. A possible reason for this is the spherical shape of fly ash particles (figure 2), which exhibits 'ball-bearing' effect and facilitates flow of the resulting composite. Hence, incorporating fly ash to partially compensate for the loss of workability due to high dosage of fibres in FRCC is recommended.

\subsection{Density}

The dry densities of the mixes at the age of 28 days are given in table 2. In general, it was noticed that the density of the $\mathrm{C}$-series specimens having higher cement content was marginally higher than that of the corresponding F-series specimens with higher fly ash content. This could be explained by the fact that cement has higher specific

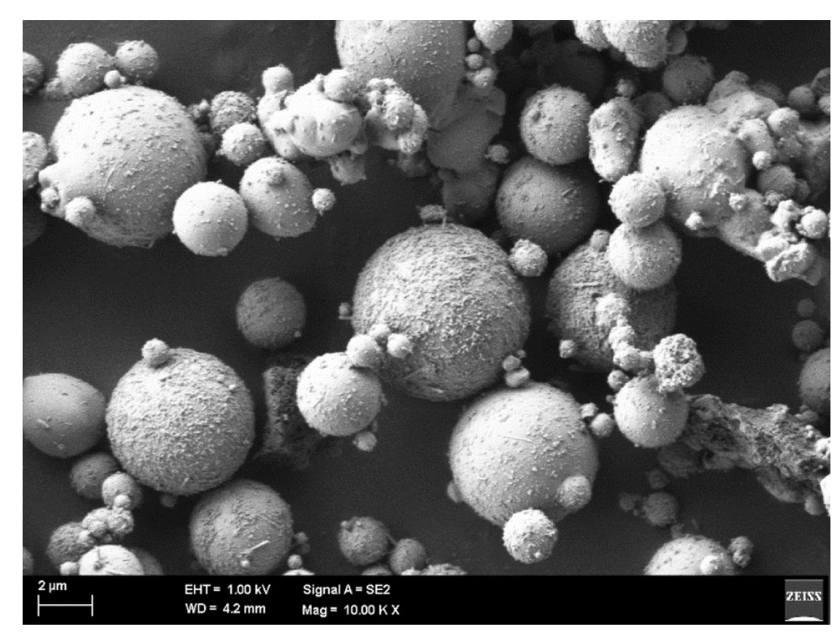

Figure 2. Spherical shape of fly ash particles. 
Table 2. Dry density of mixes at 28 days.

\begin{tabular}{lc}
\hline Mix & Density $\left(\mathrm{kg} / \mathrm{m}^{3}\right)$ \\
\hline C0 & 2137 \\
C1 & 2115 \\
C2 & 2101 \\
F0 & 2124 \\
F1 & 2025 \\
F2 & 2041 \\
\hline
\end{tabular}

gravity than fly ash, which is in agreement with previous finding [21]. However, it could be seen that upon inclusion of acrylic fibres, the density of specimens was reduced, regardless of the cement or fly ash content. This is probably because the fibres were utilized as fine aggregate substitute since the fibres had lower density than the river sand. In addition, it is possible that due to replacement of sand with fibres, there was less effective packing of the composite and this caused lower density of the composite. The fibres have higher surface area and require greater amount of binder for coating; hence, there is lower amount of binder to contribute in the packing of matrix. The introduction of air voids into composites with the inclusion of acrylic fibres was also reported in the past [17].

\subsection{Flexural strength}

The 28 days flexural strength results of all mixes are presented in figure 3. It is apparent that the inclusion of acrylic fibres significantly enhanced the tensile strength of the composite. For the case of FRCC with $1.0 \%$ fibres, the flexural strength was increased by $38 \%$ and $41 \%$, respectively, for the C-series (70:30 cement-to-fly ash ratio) and F-series (40:60 cement-to-fly ash ratio) mixes whereas the increment was up to $48 \%$ and $100 \%$ when $2 \%$ fibres were introduced in the respective FRCC. Increment in the flexural strength was likely due to the fibre bridging action, which 'stitched' the cracks as well as delayed the propagation and widening of cracks, enabling the composite to sustain higher loading before failure. The enhancement of tensile strength of mortar through the use of polymeric acrylic fibres corresponds well to previous investigations by Pakravan et al [22] and Pereira-de-Oliveira et al [17], depending on the optimum volume of fibres based on the respective mix designs.

It is also interesting to note that the enhancement in tensile strength was superior in the case of the F-series FRCC, which contained higher amount of fly ash. One of the possible reasons is the better dispersion for fibres in the F-series mix due to the higher flow caused by higher volume of fly ash. The improved dispersion reduced the tendency for fibre balling, and hence encouraged a more uniform distribution of fibres and effective fibre strengthening action in the composite. Besides that, since the

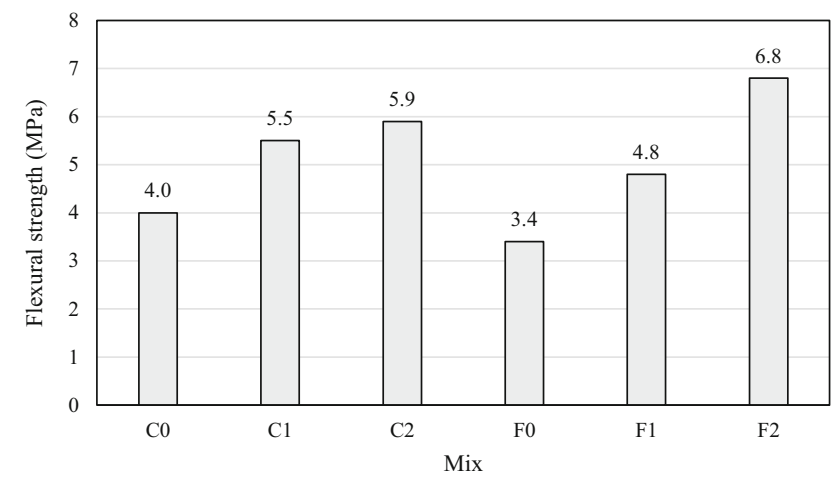

Figure 3. Flexural strength of FRCC.

F-series FRCC which contained higher amount of fly ash had lower matrix strength, the positive effect of the acrylic fibres in enhancing the flexural strength was more pronounced. This corresponds well to the previous suggestions that the effectiveness of fibres can be realized through the use of pozzolanic SCM $[12,13]$. Although it can be summarized that the inclusion of the acrylic fibres brought upon enhancement in the flexural tensile strength of the FRCC, the failure mode of the specimens was not altered compared to the control specimen without fibres. In other words, the FRCC specimens were found to fail upon widening of a single, distinct crack at the centre without any observed strain hardening behaviour when subjected to the flexural loading. A similar type of failure mode was also previously observed by Pakravan et al [22] in acrylic fibre-reinforced cement mortar.

\subsection{Compressive strength}

Based on the results in figure 4, it can be clearly seen that the 7 and 28 days compressive strengths of the C-series mixes, which contained higher amount of cement, were higher than those from the F-series with higher fly ash to cement ratio. On average, this difference was found to be about $40 \%$. The higher compressive strength of the C-series specimens is due to the higher cement content in these mixes, whereas in the F-series mixes, which had high volume of fly ash, un-hydrated fly ash particles could be present and this could have caused lower strength of the composite. Nevertheless, considering that fly ash is a pozzolanic material, the rate of strength gain of the specimen with pozzolans will be higher once pozzolanic reaction takes place. For instance, the compressive strength gain from 7 to 28 days was higher at about $62-75 \%$ for the F-series specimens compared with the increase of 54-60\% for the $\mathrm{C}$-series specimens. This is because after 28 days, the process of cement hydration is more developed, yielding higher amount of hydration products as well as calcium hydroxide as by-products. The fly ash available then 
reacted with the calcium hydroxide and produced calcium silicate hydrate, which imparted strength to the composite.

On the other hand, no significant effect on the compressive strength was found with the inclusion of the acrylic fibres. While previous reports suggested that there was marginal increase in compressive strength of concrete and

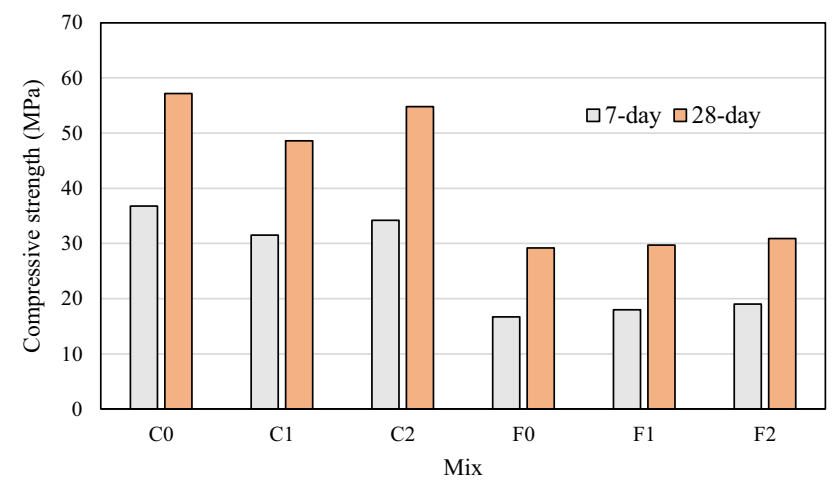

Figure 4. 7- and 28-day compressive strength of FRCC.

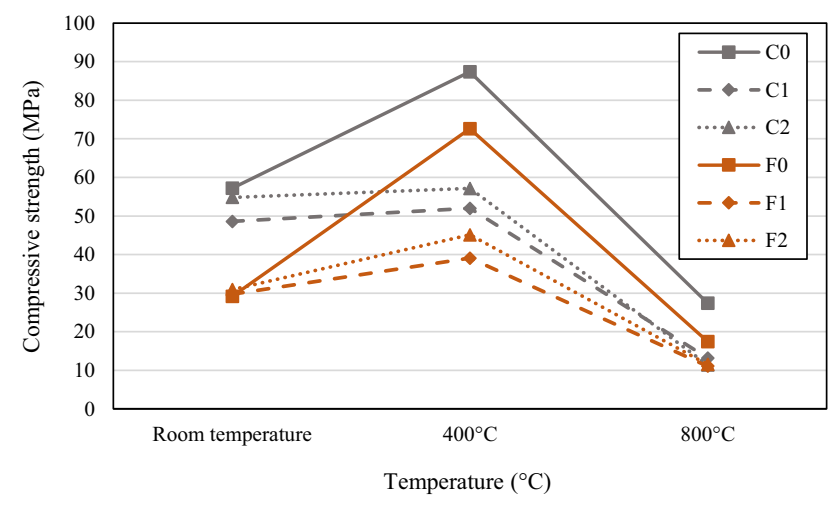

Figure 5. Effect of temperature on the compressive strength of FRCC. mortar at an optimum fibre dosage [16, 18], the disparity observed in this study could be attributed to the significantly lower dosage used previously as well as different type of binder adopted for the study. In this investigation, the high binder content allows for high volume of fibres up to $2 \%$ to be incorporated but at the same instance, there could be a disturbance effect that limited the compressive strength enhancement due to the high fibre dosage. There is a possibility of ineffective packing of the composite when there is high amount of fibres, and hence induced voids within the composite. Therefore, the introduction of these voids due to incomplete packing could have an overriding effect over the positive contribution of fibre bridging action on the compressive strength of the FRCC. The lower compressive strength obtained for the mix $\mathrm{C} 1$ could be also attributed to the random nature of fibre dispersion as well as the location of induced voids, giving inconsistency in the trends observed for the effect of fibre addition.

\subsection{Residual strength}

The comparison of residual strengths of FRCC specimens after exposure to elevated temperature in a muffle furnace is presented in figure 5. In general, it was observed that at elevated temperature of $400^{\circ} \mathrm{C}$, only hairline cracks of the specimen were observed whereas cracking can be clearly observed in specimens exposed to $800{ }^{\circ} \mathrm{C}$. The cracking of specimens at elevated temperatures of 400 and $800{ }^{\circ} \mathrm{C}$ is shown in figures 6 and 7, respectively. It can be seen that at $800{ }^{\circ} \mathrm{C}$, there was minor spalling in most of the specimens; the F-series specimens containing higher amount of fly ash had more severe spalling damage compared with the corresponding $\mathrm{C}$-series specimen. A possible explanation is the lower strength of the matrix of the former due to high amount of fly ash used. The mix F0 had the most severe spalling among all of the specimens, and it is interesting to note that the inclusion of acrylic fibres reduced the spalling significantly in FRCC specimens F1 and F2. Spalling could

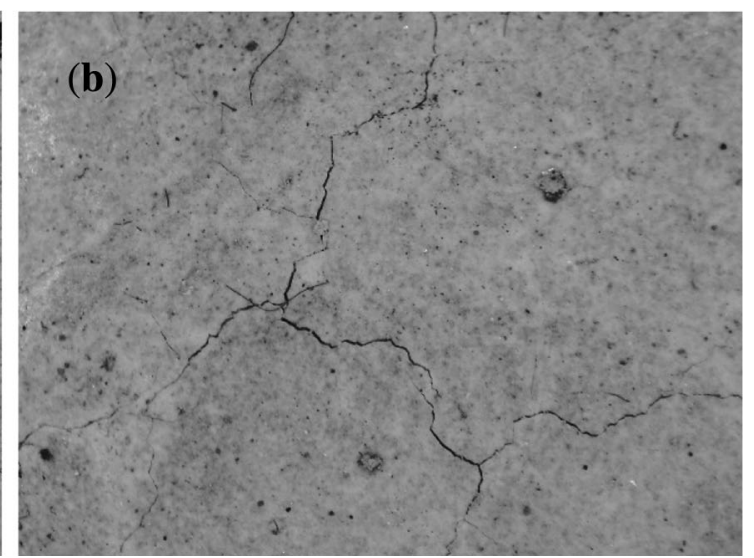

Figure 6. Hairline cracks in specimen (a) C0 and (b) F0 after exposure to $400{ }^{\circ} \mathrm{C}$. 

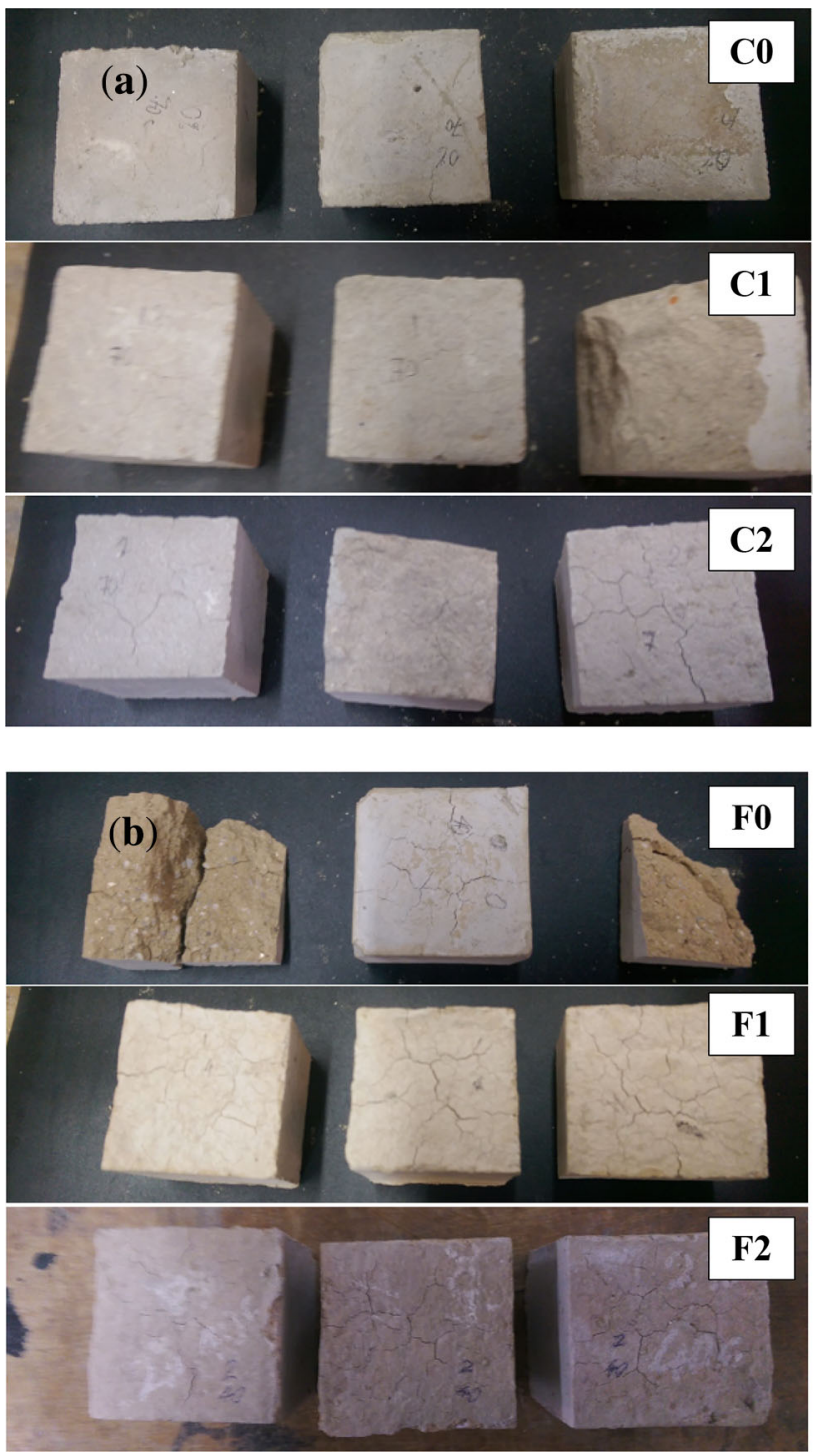

Figure 7. (a) $\mathrm{C} 0-\mathrm{C} 2$ specimens and (b) $\mathrm{F} 0-\mathrm{F} 2$ specimens after exposure to $800{ }^{\circ} \mathrm{C}$.

be prevented as a result of enhanced tensile capacity of FRCC with the use of fibres [23]; consequently there would be less cracking and the extent of cracking could be less severe.

In terms of the residual compressive strength, generally at $400{ }^{\circ} \mathrm{C}$, all of the composites exhibited increase in the residual compressive strength while at $800{ }^{\circ} \mathrm{C}$, the residual compressive strength was significantly reduced, which was in the range of $40-79 \%$. The increase in compressive strength at $400{ }^{\circ} \mathrm{C}$ could be attributed to the evaporation of free water, which induced greater van der Waals forces as the binder gel layers moved closer together [8]. Apart from this, the strength increment could be caused by the enhanced hydration of cement, which facilitated the cement-pozzolan reaction to produce more hydration products. The hydration products hence could fill up the pores within the composite and increase its bond strength [24]. It was reported that the additional hydration product produced could be tobermorite, which was much stronger than calcium silicate hydrate gel, and this was credited to the increase in compressive strength of concrete containing fly ash at $400{ }^{\circ} \mathrm{C}$ [10].

It is interesting to note that at $400{ }^{\circ} \mathrm{C}$, the increase in strength was significantly higher for the specimens without fibres, which was about $53 \%$ and $149 \%$ for specimens C0 and F0, respectively. For the corresponding specimens with fibres, the increase in strength at $400{ }^{\circ} \mathrm{C}$ was only $7 \%, 4 \%$, $32 \%$ and $46 \%$ for the FRCC specimens $\mathrm{C} 1, \mathrm{C} 2, \mathrm{~F} 1$ and F2, respectively. Voids were left behind as a result of the fibres melting at the temperature of $400{ }^{\circ} \mathrm{C}$ in the specimens with fibres. This could have created greater amount of pore space and hence the filling up of these pores with the hydration products from the enhanced cement-pozzolan reaction was less effective. Additionally, the voids present could have prevented effective packing of the binder gels by the van der Waals action as described in the earlier section. Hachemi and Ounis [25] also reported that an increase in porosity of concrete corresponds to a reduction in cohesion of the van der Waals forces.

It is also clear that the specimens with higher amount of fly ash (F-series) exhibit greater strength gain at $400{ }^{\circ} \mathrm{C}$ compared with the $\mathrm{C}$-series specimens with lower fly ash content. The higher increase in compressive strength of the F-series specimen compared with those of C-series at this temperature could be caused by the increased hydration process of the F-series specimens as explained earlier. Bhat et al [23] also suggested that higher amount of fly ash could contribute to greater increase in compressive strength at this temperature. This was also supported by the findings of Rashad [9] and Khan and Abbas [26], whereby the inclusion of blast furnace slag as partial cement replacement improved the compressive strength of concrete at $400{ }^{\circ} \mathrm{C}$, particularly at higher volume replacement, as observed by Rashad [9].

As shown in figure 4 , when the exposure temperature was increased to $800^{\circ} \mathrm{C}$, all of the composites exhibited significant strength deterioration. The loss in strength at this stage is due to the decomposition of calcium silicate hydrate [27]. In addition, the incompatibility of thermal expansion coefficients between the fine aggregates and binder may lead to bond breakdown, resulting in the loss of compressive strength [5].

At $800{ }^{\circ} \mathrm{C}$, the strength degradation was $52 \%, 73 \%$ and $79 \%$ for the $\mathrm{C}$-series mixes $\mathrm{C} 0, \mathrm{C} 1$ and $\mathrm{C} 2$, respectively, whereas the reduction was $40 \%, 63 \%$ and $63 \%$ for the F-series mixes F0, F1 and F2, respectively. It should be noted that the residual compressive strength taken for the mix F0 was based on a single specimen due to complete spalling of other two specimens. Nevertheless, it can be seen that the composites containing higher volume of fly ash had better strength retention than the respective 
counterparts with lower fly ash content when exposed to high temperatures, provided that spalling damage can be controlled. Improvement in strength retention of concrete due to the use of fly ash at such temperature was also previously reported $[9,24]$. This could be due to the formation of new mineral compounds associated with the use of fly ash at $800{ }^{\circ} \mathrm{C}$ [11]. Although the acrylic fibres were useful in controlling spalling of the F-series FRCC, higher strength reduction was found in the fibre-reinforced specimens from the $\mathrm{C}$-series which did not exhibit spalling damage. A possible reason could be the melting of fibres, which left behind a greater number of voids, hence accelerating the formation of cracks in the composite at high temperatures, leading to lower compressive strength.

\section{Conclusion}

This investigation deals with the inclusion of fly ash as partial cement substitute as well as the use of acrylic fibres to produce an FRCC. The inclusion of fly ash and fibres is necessary in producing such composite to compensate the deficiency of one another. For the enhancement of tensile strength of composite, the acrylic fibres are required but at the same time fly ash is needed to compensate for the reduction in workability as a result of the use of the fibres. From the investigation, it can be concluded that with high fly ash content, the positive effects of the fibres can be maximized in terms of the flexural strength enhancement. While there is little influence of fibres on the compressive strength, the acrylic fibres are useful in preventing severe spalling damage as well as providing higher strength retention in the FRCC containing higher amount of fly ash when the composite is exposed to elevated temperatures.

\section{Acknowledgement}

The financial support provided by University of Malaya under the grants BK050-2016 and PG163-2015A is gratefully acknowledged. The authors would also like to thank Lee Hong Jie and Bryan Ewe Onn for their assistance in the laboratory works carried out.

\section{References}

[1] Li V C, Wang S and Wu C 2001 Tensile strain-hardening behavior of polyvinyl alcohol engineered cementitious composite (PVA-ECC). ACI Mater. J. 98(6): 483-492

[2] Zhou X, Ghaffar S H, Dong W, Oladiran O and Fan M 2013 Fracture and impact properties of short discrete jute fibre-reinforced cementitious composites. Mater. Des. 49: $35-47$
[3] Tian H, Zhang Y X, Ye L and Yang C 2015 Mechanical behaviours of green hybrid fibre-reinforced cementitious composites. Constr. Build. Mater. 95: 152-163

[4] Sierra-Beltran L and Schlangen E 2012 Mechanical behaviour of wood fibre reinforced cementitious composites. In: Proceedings of the 8th RILEM International Symposium on Fibre Reinforced Concrete, Guimaraes

[5] Khan M S and Abbas H 2015 Effect of elevated temperature on the behavior of high volume fly ash concrete. KSCE J. Civ. Eng. 19(6): 1825-1831

[6] Zeiml M, Leithner D, Lackner R and Mang H A 2006 How do polypropylene fibers improve the spalling behavior of insitu concrete? Cem. Concr. Res. 36(5): 929-942

[7] Zheng W, Luo B and Wang Y 2013 Compressive and tensile properties of reactive powder concrete with steel fibres at elevated temperatures. Constr. Build. Mater. 41: 844-851

[8] Nadeem A, Memon S A and Lo T Y 2013 Mechanical performance, durability, qualitative and quantitative analysis of microstructure of fly ash and metakaolin mortar at elevated temperatures. Constr. Build. Mater. 38: 338-347

[9] Rashad A M 2015 An investigation on very high volume slag pastes subjected to elevated temperatures. Constr. Build. Mater. 74: 249-258

[10] Rashad A M 2015 An investigation of high-volume fly ash concrete blended with slag subjected to elevated temperatures. J. Clean. Prod. 93: 47-55

[11] Seleem H E D, Rashad A M and Elsokary T 2011 Effect of elevated temperature on physico-mechanical properties of blended cement concrete. Constr. Build. Mater. 25(2): 1009-1017

[12] Kayali O 2004 Effect of high volume fly ash on mechanical properties of fiber reinforced concrete. Mater. Struct. 37(5): 318-327

[13] Alhozaimy A M, Soroushian P and Mirza F 1995 Mechanical properties of polypropylene fiber reinforced concrete and the effects of pozzolanic materials. Cem. Concr. Compos. 18(2): 85-92

[14] Jang H S, So H S and So S 2016 The properties of reactive powder concrete using PP fiber and pozzolanic materials at elevated temperature. J. Build. Eng. https://doi.org/10.1016/j. jobe.2016.09.010

[15] Gao D, Yan D and Li X 2012 Splitting strength of GGBFS concrete incorporating with steel fiber and polypropylene fiber after exposure to elevated temperatures. Fire Saf. J. 54: $67-73$

[16] Mo K H, Alengaram U J, Jumaat M Z and Liu M Y J 2015 Contribution of acrylic fibre addition and ground granulated blast furnace slag on the properties of lightweight concrete. Constr. Build. Mater. 95: 686-695

[17] Pereira-de-Oliveira L A, Castro-Gomes J P and Nepomuceno M C S 2012 Effect of acrylic fibres geometry on physical, mechanical and durability properties of cement mortars. Constr. Build. Mater. 27: 189-196

[18] Mo K H, Bong C S, Alengaram U J, Jumaat M Z and Yap S P 2017 Thermal conductivity, compressive and residual strength evaluation of polymer fibre-reinforced high volume palm oil fuel ash blended mortar. Constr. Build. Mater. 130: 113-121

[19] Hsie M, Tu C and Song P S 2008 Mechanical properties of polypropylene hybrid fiber-reinforced concrete. Mater. Sci. Eng. A 494(1): 153-157 
[20] Flores Medina N, Barluenga G and Hernandez-Olivares F 2014 Enhancement of durability of concrete composites containing natural pozzolans blended cement through the use of Polypropylene fibers. Compos. Part B: Eng. 61: 214-221

[21] Akcaozoglu S and Atis C D 2011 Effect of granulated blast furnace slag and fly ash addition on the strength properties of lightweight mortars containing waste PET aggregates. Constr. Build. Mater. 25: 4052-4058

[22] Pakravan H R, Jamshidi M and Latifi M 2011 Investigation on polymeric fibers as reinforcement in cementitious composites: flexural performance. J. Ind. Text. 42(1): 3-18

[23] Bhat P S, Chang V and Li M 2014 Effect of elevated temperature on strain-hardening engineered cementitious composites. Constr. Build. Mater. 69: 370-380
[24] Heikal M, El-Didamony H, Sokkary T M and Ahmed I A 2013 Behavior of composite cement pastes containing microsilica and fly ash at elevated temperature. Constr. Build. Mater. 38: 1180-1190

[25] Hachemi S and Ounis A 2017 The influence of sand nature on the residual physical and mechanical properties of concrete after exposure to elevated temperature. Eur. J. Environ. Civ. Eng. https://doi.org/10.1080/19648189.2017.1327893

[26] Khan M S and Abbas H 2016 Performance of concrete subjected to elevated temperature. Eur. J. Environ. Civ. Eng. 20(5): 532-543

[27] Ling T C and Poon C S 2013 Stress-strain behaviour of fire exposed self-compacting glass concrete. Fire Mater. 37(4): 297-310 